\title{
HUBUNGAN PERILAKU DAN PERSONAL HYGIENE IBU DENGAN KEJADIAN KECACINGAN PADA BALITA DI WILAYAH KERJA PUSKESMAS GALANG TAHUN 2019
}

\section{FITHRI HANDAYANI LUBIS ${ }^{1}$, TRIA PUSPITA DEWI GINTING², RAWALVEN PURBA ${ }^{3}$}

\author{
FAKULTAS KESEHATAN MASYARAKAT INSTITUT KESEHATAN DELI HUSADA \\ JLN. BESAR NO. 77 DELI TUA KAB. DELI SERDANG - SUMATERA UTARA 20355 \\ e-mail :fithri.handa@gmail.com \\ DOI : https://doi.org/10.35451/jkg.v2i2.397
}

\begin{abstract}
Health behavior is all activities of a person that can be observed or which cannot be observed that are related for health care and improvement. Helminthiasis is the infectious of disease whose prevalence is very high in Indonesia, especially intestinal worms that are transmitted through soil (Soil Transmitted Helminth ). Worm disease is widespread in both rural and urban areas. The problem of this research there is relationship between behavior and personal hygiene of the mother with helminthiasis incident in infants in the work area of Galang Public Health Center in 2019. the type of research used is using survey research that is analytical survey with a cross sectional survey approach to learn the correlation dynamics between risk factors by effects, by approach, observation data colletion in the same time (point time approach). Population of the research 160 mothers the sample of this research is 62 mothers that have baby in Galang Public Health Center . the variable of the researched to knowing about relationship behavior and personal hygiene of the mother with helminthiasis incident as independent variable and helminthiasis in infant as dependent variable .the Data is by questionnaire technique. The Data obtained were analyzed using univariate and bivariate analysis. The result of the research showed that based on personal hygiene mothers who behaved adequately as many as 39 peoples $(62,9 \%)$ while the mothers who behaved had good hygiene was 23 people $(37,1)$. The result showed that helminthiasis incident in infants as many as 39 peoples $(62.9 \%)$ research while those who did not develop helminthiasis in infants were 23 peoples $(37.1 \%)$. The result of chisquare test a many as.. with $p$ value $0.007(p<0.05)$ that means $\mathrm{Ho}$ is rejected and Ha accepted. There in significant relationship between behavior and personal hygiene of the mother with helminthiasis incident in infanst in the work area of Galang Public Health Center in 2019.
\end{abstract}

Keywords: behaviour, personal hygiene, infant, helminthiasis incident. 


\section{Pendahuluan}

Hingga saat ini di Negara Indonesia, Kejadian Kecacingan masih menjadi penyakit infeksi dengan prevalensi yang cukup tinggi, infeksi kecacingan yang paling utama yaitu infeksi cacing usus yang ditularkan melalui tanah atau dikenal dengan istilah Soil Transmitted Helminth (STH).

Penyakit infeksi kecacingan masih tersebar luas hingga saat ini baik di daerah pedesaan maupun di pemukiman masyarakat perkotaan (Endriani, 2010), adapun Definisi infeksi kecacingan menurut WHO (2011) yaitu infeksi satu atau lebih cacing parasit golongan nematoda yang menginfeksi usus manusia.

Data dari World Health Organization (WHO) pada tahun 2015 menyebutkan bahwa lebih dari 1,5 miliar orang atau $24 \%$ dari populasi dunia terinfeksi oleh parasit yang ditularkan melalui tanah. Angka infeksi cacing tertinggi tercatat ditemukan di Sub-Sahara Negara Afrika, Negara Amerika, Negara Cina dan beberapa negara Asia Timur ( Sevfianti, 2016).

Sebagai negara yang masih dalam klasifikasi negara berkembang, Hingga saat ini Indonesia masih menghadapi tingkat penyakit infeksi yang tinggi, terutama penyakit infeksi yang berkaitan dengan kondisi sanitasi lingkungan yang masih kurang baik. Salah satu penyakit yang insidennya masih tinggi adalah infeksi kecacingan yang merupakan salah satu penyakit yang menginfeksi melalui lingkungan. Hal itu dinilai sangat wajar jika dilihat antropologi Indonesia yang merupakan negara agraris dengan tingkat sosial ekonomi, pengetahuan, keadaan sanitasi lingkungan dan tingkat higiene perorangan masyarakat yang masih cenderung rendah sehingga mempermudah proses infeksi cacing (Rizka, 2013).

Prevalensi Cacingan di Indonesia hingga saat ini masih tinggi, sekitar $60 \%-80 \%$ kejadian infeksi. Kondisi geografis Indonesia yang memiliki temperatur dan kelembaban yang tinggi dan sangat sesuai sebagai tempat perkembangbiakan cacing parasit usus. Hal tersebut tergambar pada Data Dinas Kesehatan Kota Manado yang mengungkapkan bahwa tingkat kasus kecacingan di kota Manado pada tahun 2012 sebanyak 102 kasus dan kasus terbanyak ditemukkan di wilayah kerja Puskesmas Bengkol yaitu sebanyak 32 kasus infeksi (Mustafa, 2013).

Data yang sama juga ditemukan dalam penelitian yang dilakukan terhadap balita, dengan Populasi ibu yang mempunyai anak balita yang datang ke posyandu Sentosa di Kota Medan tahun 2016. Berdasarkan hasil pemeriksaan Tinja pada respponden penelitian, ditemukan bahwa sikap ibu berpengaruh terhadap infeksi cacingan pada balita (Rahayu, 2019).

Di Sumatera Utara khususnya kota Medan prevalensi kecacingan pada anak sekitar (60-70\%) dari semua kasus (Daulay, 2010). Melalui Survey awal peneliti pada bulan Agustus Tahun 2019 di Puskesmas Galang dari 45 orang ibu yang mempunyai balita dengan menggunakan wawancara dan membagikan pernyataan berbentuk angket di dapatkan data bahwa 36 ibu belum memahami bagaimana perilaku ibu yang mempunyai balita dengan menggunakan wawancara dan membagikan pernyataan berbentuk angket di dapatkan data bahwa 36 ibu belum memahami bagaimana perilaku ibu yang sesungguhnya yang dapat menyebabkan kejadian kecacingan pada balita. 


\section{METODE}

Rancangan penelitian ini menggunakan penelitian survey yang bersifat survei analitik dengan pendekatan cross sectional yaitu dengan cara mengumpulkan data variabel independen dan data variabel dependen yang dilakukan secara bersamaan atau sekaligus. Untuk itu peneliti ingin mengetahui hubungan perilaku dan personal hygiene ibu dengan kejadian kecacingan pada balita di Wilayah Kerja Puskesmas Galang Tahun 2019. Populasi dalam penelitian ini adalah Ibu yang memiliki balita di Puskesmas Galang dengan jumlah 160 balita di bulan Desember 2019. Pengambilan sampel dalam penelitian ini adalah Ibu yang memiliki balita yang berada di Wilayah Kerja Puskesmas Galang 2019 pada saat melakukan penelitian. Teknik pengambilan sampel yang memberikan peluang yang sama bagi setiap unsur (Probability Sampling). Dalam Probalitiy sampling sesuai polulasi teknik pengambilan sampel yang digunakan adalah Stratified Random sampling. Untuk sampel penelitian, peneliti menggunakan rumus slovin untuk menentukan besar jumlah sampel yang akan diteliti. Analisa Univariat dilakukan untuk melihat distribusi frekuensi dan persentase dari setiap variabel dependen dan independen. (Notoatmodjo, 2012). Variabel tersebut adalah kejadian kecacingan pada balita. Analisa Bivariat Analisa yang digunakan untuk mengetahui hubungan dari masingmasing variabel independen (Notoatmodjo, 2012) yaitu Perilaku dan tindakan personal hygiene ibu dengan variabel dependen yaitu kejadian kecacingan pada balita. Uji analisa dengan menggunakan uji chi-square pada taraf kepercayaan $95 \%(0,05)$ sehingga diketahui hubungan antar variabel penelitian.

\section{HASIL}

Hasil pengumpulan data mengenai karakteristik responden di wilayah kerja Puskesmas Galang di ketahui bahwa mayoritas responden yang berumur 20 - 25 tahun ( 40,\%), sebagian besar ibu yang yang berpendidikan responden sebesar adalah SMA (57\%),Sebagaian besar ibu rumah tangga yaitu ( $42 \%$ ), sebagian besar ibu - ibu memiliki usia anak 1- 2 tahun (29\%), sedangkan untuk usia anak paling banyak adalah 2 - 3 Tahun (58\%) dan Sebagaian besar anak 3 - 5 Tahun sebanyak (13\%).

\section{Karakteristik Responden}

Tabel 1. Karakteristik Responden

\begin{tabular}{lcc}
\hline Karakteristik & F & $\mathbf{\%}$ \\
\hline $\begin{array}{l}\text { Pendidikan } \\
\text { SMA }\end{array}$ & 35 & 57 \\
\hline Diploma, S1 & 19 & 31 \\
\hline S2 & 8 & 12 \\
\hline Total & 62 & 100 \\
\hline
\end{tabular}

Umur

\begin{tabular}{lcc}
\hline $20-30$ & 25 & 40 \\
\hline $25-30$ & 19 & 30 \\
\hline $30-35$ & 12 & 20 \\
\hline$>35$ & 6 & 10 \\
\hline Total & 62 & 100 \\
\hline Pekerjaan & & \\
\hline Wiraswasta & 18 & 29 \\
\hline $\begin{array}{l}\text { Ibu Rumah } \\
\text { Tangga }\end{array}$ & 26 & 42 \\
\hline PNS & 11 & 18 \\
\hline Pegawai Swasta & 7 & 11 \\
\hline Total & 62 & 100 \\
\hline
\end{tabular}




\section{Umur Balita}

\begin{tabular}{lcc}
\hline $1-2$ Tahun & 18 & 29 \\
\hline $2-3$ Tahun & 36 & 58 \\
\hline $3-5$ Tahun & 8 & 13 \\
\hline Total & 62 & 100
\end{tabular}

Jenis Kelamin Balita

\begin{tabular}{lcc}
\hline Laki - Laki & 32 & 52 \\
\hline Perempuan & 30 & 48 \\
\hline Total & 62 & 100
\end{tabular}

\section{ANALISIS UNIVARIAT}

Tabel 2 Distribusi responden berdasarkan Personal Hygiene

\begin{tabular}{lcc}
\hline Personal Hygiene & F & \% \\
& & \\
\hline Cukup & 39 & 62,9 \\
Baik & 23 & 37,1 \\
\hline Total & 62 & 100
\end{tabular}

Berdasarkan tabel diatas maka dilihat bahwa mayoritas responden yang Personal Hygiene Ibu Cukup sebanyak 39 orang (62,9\%) dan minoritas responden yang Personal Hygiene ibu baik yaitu sebanyak 23 orang $(37,1 \%)$. Berdasarkan Hasil penelitian distribusi kejadian Kecacingan pada balita dapat dilihat pada tabel berikut ini.
Tabel 3 Berdasarkan Kejadian Kecacingan

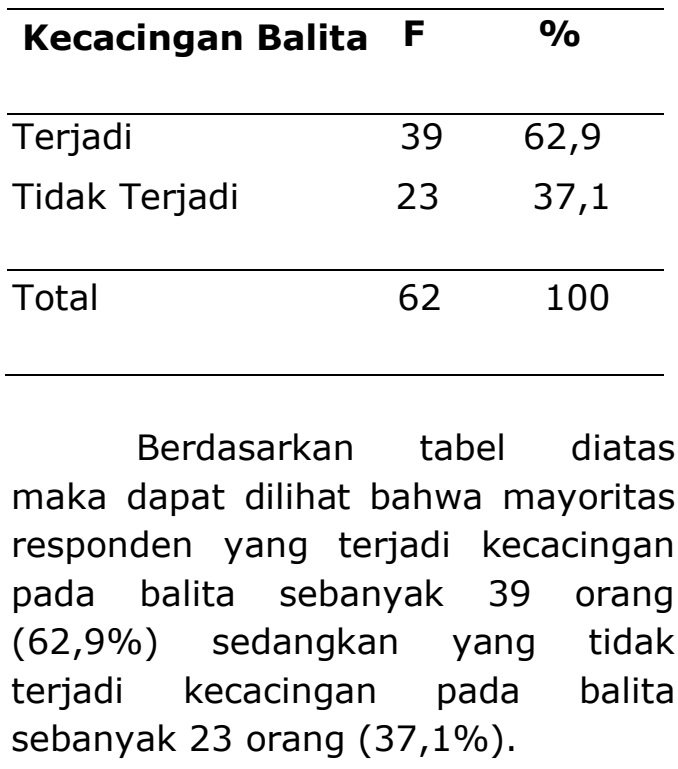

\section{ANALISIS BIVARIAT}

Tabel 4 distribusi Responden Berdasarkan Hubungan Perilaku ibu dengan Kejadian Kecacingan Pada Balita.

\begin{tabular}{|c|c|c|c|c|c|c|c|}
\hline \multirow[b]{2}{*}{$\begin{array}{l}\text { Pen } \\
\text { get } \\
\text { ahu } \\
\text { an } \\
\text { Ibu }\end{array}$} & \multicolumn{4}{|c|}{$\begin{array}{c}\text { Kejadian } \\
\text { Kecacingan }\end{array}$} & \multicolumn{2}{|c|}{ Total } & \multirow[t]{2}{*}{$\begin{array}{c}\text { P- } \\
\text { Val } \\
\text { ue }\end{array}$} \\
\hline & \multicolumn{2}{|c|}{$\begin{array}{l}\text { Terja } \\
\text { di } \\
\text { Keca } \\
\text { cing } \\
\text { an }\end{array}$} & \multicolumn{2}{|c|}{$\begin{array}{l}\text { Tidak } \\
\text { Terjadi } \\
\text { Kecacin } \\
\text { gan }\end{array}$} & & & \\
\hline & $n$ & $\%$ & $\mathrm{n}$ & $\%$ & $n$ & $\%$ & \\
\hline Cuk & 3 & 51, & 10 & 16 & 42 & 6 & \\
\hline up & 2 & 6 & &, 1 & & $\begin{array}{l}7, \\
7\end{array}$ & \\
\hline Baik & 7 & $\begin{array}{l}11 \\
3\end{array}$ & 13 & 21 & 20 & $\begin{array}{l}3 \\
2, \\
3\end{array}$ & $\begin{array}{c}0,0 \\
04\end{array}$ \\
\hline $\begin{array}{l}\text { Tot } \\
\text { al }\end{array}$ & $\begin{array}{l}4 \\
0\end{array}$ & $\begin{array}{l}67 \\
7\end{array}$ & $\begin{array}{l}2 \\
3\end{array}$ & $\begin{array}{l}3 \\
2 \\
1 \\
3\end{array}$ & $\begin{array}{l}6 \\
2\end{array}$ & $\begin{array}{l}1 \\
0 \\
0\end{array}$ & \\
\hline
\end{tabular}

Berdasarkan tabel diatas , dapat dilihat bahwa 42 responden ibu yang perilaku cukup pada kejadian kecacingan pada balita mayoritas 
sebanyak 32 orang $(76,2 \%)$ dan ibu berperilaku baik pada kejadian kecacingan pada balita sebanyak 20 orang, ibu yang berperilaku baik sebanyak 7 orang $(35,0)$.

Hasil uji statistik diperoleh nilai $p=0,004$ dimana $p<0,05$ artinya ada hubungan perilaku ibu dengan kejadian kecacingan pada balita di Puskesmas Galang 2019.

Tabel 5 distribusi Responden

Berdasarkan Hubungan Personal Hygiene ibu dengan Kejadian Kecacingan Pada Balita

\begin{tabular}{|c|c|c|c|c|c|c|c|}
\hline \multirow{3}{*}{$\begin{array}{l}\text { Perso } \\
\text { nal } \\
\text { Hygie } \\
\text { ne }\end{array}$} & \multicolumn{7}{|c|}{ Kejadian Kecacingan } \\
\hline & \multicolumn{2}{|c|}{$\begin{array}{l}\text { Terjad } \\
\text { i } \\
\text { kecaci } \\
\text { ng an }\end{array}$} & \multicolumn{2}{|c|}{$\begin{array}{l}\text { Tidak } \\
\text { Terja } \\
\text { di } \\
\text { Keca } \\
\text { cin } \\
\text { gan }\end{array}$} & \multicolumn{2}{|c|}{ Total } & \multirow[t]{2}{*}{$\begin{array}{l}\text { P- } \\
\text { val } \\
\text { ue }\end{array}$} \\
\hline & $\mathbf{n}$ & $\%$ & $\mathbf{n}$ & $\%$ & $\mathbf{n}$ & $\%$ & \\
\hline Cukup & $\begin{array}{l}3 \\
0\end{array}$ & $\begin{array}{c}76, \\
9\end{array}$ & 9 & $\begin{array}{c}23 \\
1\end{array}$ & 39 & 62,9 & \\
\hline & & & & & & & 0,0 \\
\hline Baik & 9 & $\begin{array}{c}39, \\
1\end{array}$ & 14 & $\begin{array}{c}60 \\
9\end{array}$ & 23 & 37,1 & 04 \\
\hline Total & $\begin{array}{l}3 \\
9\end{array}$ & $\begin{array}{c}62, \\
9\end{array}$ & 23 & $\begin{array}{c}37 \\
1\end{array}$ & 62 & 100 & \\
\hline
\end{tabular}

\section{KESIMPULAN}

Berdasarkan Hasil Penelitian di Wilayah Kerja Puskesmas Galang Tentang Hubungan Perilaku dan Personal Hygiene Ibu dengan Kejadian Kecacingan Pada Balita

1. 1. Terdapat $32 \quad(51,6 \%)$ responden memiliki Perilaku yang cukup baik dan sebanyak $7(11,3 \%)$ responden yang baik.

2. Terdapat 39 (62,9\%) anak balita yang terkena kecacingan sedangkan 23( $37,1 \%)$ anak yang tidak terkena kecacingan.
3. Terdapat hubungan Perilaku ibu dengan Kejadian kecacingan pada Balita di Wilayah Kerja Puskesmas Galang . Hasil uji statistik diperoleh nilai $p=0,004$ dimana $p<0,05$.

4. Terdapat hubungan Personal Hygiene ibu dengan Kejadian kecacingan pada Balita di Wilayah Kerja Puskesmas Galang. Hasil uji statistik diperoleh nilai $\mathrm{p}$ $=0,007$ dimana $p<0,05$

\section{DAFTARPUSTAKA}

Anwar Yunidha Rizka,dkk. Hubungan Antara Higiene Perorangan Dengan Infeksi Cacing Usus ( Soil Transmitted Helminths) Pada Siswa SDN 25 dan 28 Kelurahan Purus, Kota Padang Sumatera Barat Tahun 2013. http:// Jurnal. Fk. Unad.ac,id.

Andarmoyo S, dkk 2012. Personal Hygiene Konsep, proses, dan aplikasi dalam Praktik Keperawatan . Graha IImu. Yogyakarta.

Arikunto Suharsimi, 2014. Prosedur Penelitian Suatu Pendekatan Praktik .Rineka Cipta. Jakarta.

Chadijah Sitti, dkk.2014. Hubungan Pengetahuan, Perilaku dan Sanitasi Lingkungan Dengan Angka Kecacingan Pada Anak Sekolah Dasar di Kota Palu, media litbang kes vol 24 no 1 Mar 2014. 50-56.

Daulay Siti A, 2010. Perilaku Ibu yang memiliki anak usia SD dalam mencegah penyakit kecacingan pada anak dikelurahan Bandar Selamat Kecamatan Medan Tembung. Fakultas Kesehatan Masyarakat Universitas Sumatera Utara.

Depkes RI,2012. Profil Kesehatan Indonesia Tahun 2011. Jakarta. 
Hanif Diah Irfan,dkk. Gambaran Pengetahuan Penyakit cacing pada wali murid SDN 1,2,3 dan 4 Mulyo Agung Kecamatan Dau Kabupaten Malang, Jawa Timur, Jurnal prefentiah Juli 2017 .

Keputusan Menteri Kesehatan Republik Indonesia nomor 424/menkes/VI/2006. Tentang Pedoman Pengendalian Cacingan.

Lubis Rahayu,dkk. Pengaruh tingkat pengetahuan dan sikap ibu terhadap kecacingan pada balita. Jurnal Kesehatan Lingkungan Indonesia . Info Artikel: Diterima Januari 2019 :Disetujui Febuari 2019 : DiPublikasi April 2019

Marlina Leni,dkk. Hubungan Pendidikan Formal, Pengetahuan Ibu dan sosial ekonomi terhadap infeksi Soiltransmed helminthes pada anak sekolah dasar di kecamatan Seluma Timur Kabupaten Seluma Bengkulu, Jurnal Ekologi Kesehatan

Mustafa Preliana,dkk. Hubungan Antara Perilaku tentang Pencegahan Penyakit Kecacingan dengan infestasi cacing pada siswa SD di Kelurahan Bengkol Kecamatan Mapanget Kota Manado, Bidang Minat Kesling. Fakultas Kesehatan Masyarakat Universitas Sam Ratulangi,2013.

Mustikawati Intan Silviana. Hubungan Pengetahuan Ibu tentang Personal Hygiene Dengan Perilaku Personal Hygiene di Rw. 04 Bantara Sungai Ciliwung, Kelurahan Manggarai, Jakarta . Universitas Esa Unggulan Jakarta, Jurnal 1 nohim Volume 1 Nomor 2 Desember 2013

Notoatmodjo Soekdjo. 2016.IImu Perilaku Kesehatan . Rineka Cipta. Jakarta.

Peraturan Menteri Kesehatan Republik Indonesia / Nomor 15 Tahun 2017/ Tentang Penanggulangan
Cacing Sevfianti, dkk. Hubungan Pencemaran Tanah Oleh Telur Soil Transmitted Helminths Pada anak sekolah Dasar Negeri 01 Karawang Sari, Medulal Volume 71 nomor 51 Desember 2017

Widoyono dr.2011. Penyakit Tropis Epedimologi PenularanPencegahan, Dan Pemberantasan, Edisi Kedua. Erlangga, Jakarta. 